\title{
Promoting the proper use of medicines in rural school children of India
}

\author{
Mangesh A. Bankar ${ }^{1}$, Sujata S. Dudhgaonkar ${ }^{2}$
}

${ }^{1}$ Department of Pharmacology, Government Medical College, Nagpur, India

${ }^{2}$ Department of Pharmacology, Indira Gandhi Medical College, Nagpur, India

Received: 16 April 2013

Accepted: 10 May 2013

\section{*Correspondence to:}

Dr. Mangesh A. Bankar,

Email:

drmangesh_bankar@yahoo.co.in

(C) 2013 Bankar MA et al. This is an open-access article distributed under the terms of the Creative Commons Attribution License, which permits unrestricted use, distribution, and reproduction in any medium, provided the original work is properly cited.

\begin{abstract}
Background: The problem of irrational use of medicines is prevalent in rural India. For safe and proper use of medicines there is a need to understand the proper way of taking medicines. Teaching proper use of medicines is the most neglected domain of the school health curriculum. So this study targeted school going children in rural area of India as the earlier the intervention, the more firmly longer lasting health related behavior can be successfully inculcated. The objectives of the study were (1) To study base level knowledge about use of medicines and (2) To implement and see the effect of an intervention to increase medicine knowledge in the form of information, education and communication (IEC) in rural school children.
\end{abstract}

Methods: This was an interventional, questionnaire based (quantitative) study in which an intervention in the form of lectures which was given to school children. Rural school going children in age group of 13-15 years were selected from 3 different schools of rural areas of Nagpur district, India. 500 school children were included after obtaining permission from school authorities and informed consent from their parents. Pretesting done by administering a questionnaire containing 20 questions to assess children's base level knowledge about medicine use. The same questionnaire was repeated on 16th and 45th day of intervention i.e. daily lectures of 25-30 minutes for 15 days on proper use of medicines, to judge the improvement.

Results: It was observed that the interventions brought about a positive change in the knowledge of the students as well as increased awareness about proper use of medicines.

Conclusions: This study showed that properly timed and meticulously implemented intervention can bring about a positive change in the attitude and knowledge of school children.

Keywords: Medicine perceptions, Knowledge, Self medication, School health, Curriculum, Adverse effects

\section{INTRODUCTION}

Previous studies have shown that harmful medicine use practices among children including independent buying and use of over the counter medicines, sharing of medicines, use of medicines for minor health ailments without informing their parents etc. are more common than expected and this has been increasingly recognized as an important factor for occurrence of adverse effects in this age group. ${ }^{1}$ Many researchers have cited the importance of educating proper medicine use to the children because most of the other developmental milestones, skill of using medicines properly is also shaped early in their life. Previously it was believed that children's ability to understand health and medicine related education is beyond their cognitive capacity and so they should not be given medicine related education. Many subsequent studies proved this theory wrong. ${ }^{2,3}$

Medicine use is among the most common health related activities children encounter during their day to day activities. Children mainly gain knowledge about medicine use by observing family members, by taking medicines themselves, by watching television and 
movies, by exposure to media advertising, and through visiting places where medicines are sold. ${ }^{4}$

Various problems of medicine use are prevalent in India. Sometimes people do not use medicines as told by their doctor like not buying the full course of medicines mainly due to financial constraints or forgetting the details of the advice given by their doctor. Many medicines should be sold on prescription only can be purchased over the counter and people generally lack knowledge about using these medicines properly. Many people needlessly overuse antimicrobials for minor diseases. They also demand to prescribe injections to their doctors. Also many systems of traditional medicines exist in India and people generally use them simultaneously along with modern allopathic medicines which some time can result in harmful drug interactions. Knowing the level of knowledge and attitude of school children will obviously be a reflection of their parent's practices of medicine use as child learn mostly by watching health behavior of his parents. $5,6,7$

For safe and proper use of medicines there is a need to understand the proper way of taking medicines. Teaching proper use of medicines is the most neglected domain of school health curriculum, especially in developing economies. Being the future users of medicines, it is of utmost importance to know the level of knowledge and attitudes of the school children regarding proper use of medicines. Considering poor health care facilities in rural areas, widespread problem of irrational use of medicines and prevalent illiteracy in the community, inclusion of these students and knowing their attitude and knowledge regarding proper medicine use will be important to formulate curriculum regarding proper use of medicines to them. ${ }^{8}$ As scarce amount of data is available regarding the knowledge and attitude of school children on proper use of medicines especially in rural areas, this study was targeting the school going children in rural areas as earlier the intervention i.e. teaching to create awareness about proper medicine use among school children, so that longer lasting health related behavior can be successfully inculcated into them. Following were the main objectives of the study:

1) To study of base level knowledge about use of medicines in school children

2) To implement an intervention in the form of information, education and communication (IEC) to increase medicine knowledge among rural school children

3) To see the effect of IEC on the awareness about proper use of medicines in school children.

\section{METHODS}

Design: This was an interventional study in which data were collected using a questionnaire. We tried to keep the questionnaire short and as simple as possible keeping in mind the age group of the participants. It was very important to accurately assess the level of knowledge of medicine use in school children, so based on the objectives of this study we included only 20 questions in the questionnaire. We tried to cover most aspects of the proper use of medicines. The questionnaire was prepared in both local as well as national languages i.e. Marathi and Hindi respectively. The questionnaire was finalized only after peer reviewing by experts. To judge the aptness of the questionnaire in line with the study objectives, we pre-tested this questionnaire on a group of 10 students who were not included in this study. The study protocol was approved by Institutional Ethics Committee of Government Medical College, Nagpur. In this study level of awareness about proper use of medicines in rural school children was compared before and after giving an intervention in the form of lectures to the school children.

Setting: This study was conducted at district level i.e. rural school going children in the age group of 13-15 years were selected from 3 different schools of rural areas of Nagpur district, India. All schools i.e. Saibaba Ashram School, Kandri, Jawahar High school and Junior artsscience college, Khapa and Jijamata High school, Khapa were located in remote areas of the Nagpur district. School children studying in VIII ${ }^{\text {th }}$ and IX $^{\text {th }}$ standards were included in this study.

Study Population: 500 high school children were included in this study after obtaining permission from school authorities and informed consent from their parents. From Jijamata High School and Jawahar High school and Junior arts-science College, we obtained 200 participants each while 100 participants were from Saibaba Ashram School, Kandri.

Interventions: The questionnaire was consisted of total 20 questions out of which 18 questions were of objective type in which student needed to mark his choice out of three options as "Yes", "No" and "Don't Know". For remaining two questions, student needed to mark as many correct answers he feels right out of four choices. No time limit was given to answer the questionnaire but students were prohibited from discussing with others except with the concerned class teacher. Also it was specifically explained to students that this questionnaire carries no marks and not designed to test their general knowledge. Initially special one hour session was conducted to aware all the teachers helping to conduct this study voluntarily. Purpose and procedure of the study was explained to them in that session. All the doubts related to proper use of medicines were answered during that session.

After explaining about the research project to the school children, pretesting was done by administering a questionnaire containing 20 questions to assess children's base level knowledge about medicine use. Teaching material related to proper use of medicines was distributed to teachers and requested to teach children daily for 15-30 minutes for 15days. Such small sessions 
were preferred to avoid encroachment on their regular studies. Information leaflet related to proper use of medicines were distributed to students. Also, posters related to proper use of medicines were displayed near the notice boards so students could see them easily. Teachers were requested to constantly reinforce students to read the educational posters. After 15 days one hour lecture on rational use of medicine was given to school children. Lecture in the form of Power Point presentation was given in which proper use of medicines was explained to school children using pictures and suitable examples appropriate to their cognitive level. All the queries by school children were answered after the lecture. After the lecture, same questionnaire was administered again to judge the improvement. Another post test was conducted again 30 days after the pretest to know the level of retained knowledge. No lectures were given between two post tests. The statistical analysis was done by using SPSS version 15 and McNemar-Bowker Test was used to compare the data of post-tests to the baseline \& $\mathrm{P}<0.05$ was considered significant.
The present study was conducted to know the baseline knowledge about the medicine in rural school children and the effect of intervention in the form of information, education and communication to the children. Out of 500 school children participated in this study, $46 \%$ were boys and $54 \%$ were girls. From the results presented in table 1, it is clear that post intervention there is increased awareness about misuse of analgesics and vitamin preparations. However no significant change in the knowledge regarding dangers of sharing of own medicines with others, dangers of using degraded medicines and giving complete information about medicines that patients is already taking was observed. Awareness increased significantly (Post test 1 - 30\%; post test $2-31 \%$ ) regarding the fact that not all the medicines need to be taken empty stomach. Some common misconceptions like injections are always more effective and safer than tablets were routed out post intervention $(\mathrm{P}<0.0001)$. Similarly misconceptions about traditional medicines like ayurvedic medicines are devoid of any adverse effects or they have no expiry date are cleared post intervention $(\mathrm{P}<0.0001)$.

\section{RESULTS}

Table 1: Participant's responses to questions.

\begin{tabular}{|c|c|c|c|c|c|c|c|c|c|c|c|}
\hline \multirow{2}{*}{ Questions } & \multicolumn{4}{|c|}{ Pre-test } & \multicolumn{4}{|c|}{ Post test 1} & \multicolumn{3}{|c|}{ Repeat Post test } \\
\hline & Yes & No & D.K. & Yes & No & D.K. & & Yes & No & D.K. & \\
\hline $\begin{array}{l}\text { 1. Sharing of medicine with } \\
\text { a friend having similar } \\
\text { complaints }\end{array}$ & 17.6 & 79.8 & 2.6 & 15 & 83.8 & 1.2 & & 16.4 & 81.8 & 1.8 & \\
\hline $\begin{array}{l}\text { 2. Analgesics are extremely } \\
\text { safe }\end{array}$ & 34.4 & 60.2 & 5.4 & 18.6 & 80.4 & 1 & $* * *$ & 23.2 & 75 & 1.8 & \#\#\# \\
\hline $\begin{array}{l}\text { 3.Doctor should be } \\
\text { informed about medicines } \\
\text { you are already taking }\end{array}$ & 89 & 10.6 & 0.4 & 90.4 & 9.4 & 0.2 & & 93 & 6.8 & 0.2 & \\
\hline $\begin{array}{l}\text { 4. Injections are more } \\
\text { effective than tablets }\end{array}$ & 79.2 & 15 & 5.8 & 22.4 & 76.6 & 1 & $* * *$ & 18.2 & 80.6 & 1.2 & \#\#\# \\
\hline $\begin{array}{l}\text { 5. All medicines should be } \\
\text { taken on empty stomach }\end{array}$ & 66 & 26.8 & 7.2 & 68.8 & 30 & 1.2 & $* * *$ & 67.6 & 31 & 1.4 & \#\#\# \\
\hline $\begin{array}{l}\text { 6. Vitamins are generally } \\
\text { safe even after overuse }\end{array}$ & 42.4 & 39 & 18.6 & 21 & 77.2 & 1.8 & $* * *$ & 24.4 & 74.4 & 1.2 & \#\#\# \\
\hline $\begin{array}{l}\text { 7. Use previously leftover } \\
\text { antibiotics if same } \\
\text { complaints }\end{array}$ & 40 & 56.2 & 3.8 & 17.6 & 80.6 & 1.8 & $* * *$ & 19.2 & 79.4 & 1.4 & \#\#\# \\
\hline $\begin{array}{l}\text { 8. Breaking or crushing the } \\
\text { tablet/capsule before using }\end{array}$ & 41.2 & 44.2 & 14.6 & 20 & 79.4 & 0.6 & $* * *$ & 16.6 & 82 & 1.4 & \#\#\# \\
\hline $\begin{array}{l}\text { 9. Take double dose next } \\
\text { day if you missed any dose }\end{array}$ & 19.6 & 74.2 & 6.2 & 9.8 & 89.2 & 1 & $* * *$ & 7.4 & 91.8 & 0.8 & \#\#\# \\
\hline $\begin{array}{l}\text { 10. Taking high dose of } \\
\text { medicine speed up } \\
\text { recovery }\end{array}$ & 15.2 & 79.6 & 5.2 & 9.8 & 89.4 & 0.8 & $* * *$ & 11.4 & 87 & 1.6 & \# \\
\hline $\begin{array}{l}\text { 11. Herbal medicines do } \\
\text { not have any side effects }\end{array}$ & 57.6 & 38.6 & 3.8 & 17.6 & 82 & 0.4 & $* * *$ & 22.2 & 77 & 0.8 & \#\#\# \\
\hline $\begin{array}{l}\text { 12. Costly medicines are } \\
\text { better than cheaper ones. }\end{array}$ & 26.8 & 62.2 & 11 & 14.8 & 84.4 & 0.8 & $* * *$ & 17.4 & 81.6 & 1 & \#\#\# \\
\hline 13. New symptom during & 59.6 & 22.4 & 18 & 65.8 & 32.6 & 1.6 & $* * *$ & 67.8 & 31 & 1.2 & \#\#\# \\
\hline
\end{tabular}




\begin{tabular}{|c|c|c|c|c|c|c|c|c|c|c|c|}
\hline \multicolumn{12}{|l|}{$\begin{array}{l}\text { treatment can be adverse } \\
\text { reaction }\end{array}$} \\
\hline $\begin{array}{l}\text { 14. Stop taking medicines } \\
\text { as soon as symptoms } \\
\text { disappear }\end{array}$ & 31 & 65.8 & 3.2 & 11.2 & 88 & 0.8 & $* * *$ & 13 & 85.8 & 1.2 & \#\#\# \\
\hline $\begin{array}{l}\text { 15. moist broken tablets } \\
\text { should not be used }\end{array}$ & 10.6 & 87.2 & 2.2 & 12.4 & 86.4 & 1.2 & & 12.2 & 86.6 & 1.2 & \\
\hline $\begin{array}{l}\text { 16. Antibiotic is used for } \\
\text { treatment of infection }\end{array}$ & 34.8 & 38 & 27.2 & 71.2 & 27.8 & 1 & $* * *$ & 67.2 & 31.2 & 1.6 & \#\#\# \\
\hline $\begin{array}{l}\text { 17. Antibiotic should be } \\
\text { used for minor illnesses }\end{array}$ & 41.4 & 45 & 13.6 & 16 & 83.4 & 0.6 & $* * *$ & 21.4 & 78 & 0.6 & \#\#\# \\
\hline $\begin{array}{l}\text { 18. Ayurvedic medicines } \\
\text { do not have any expiry date }\end{array}$ & 39.2 & 37 & 23.8 & 18.4 & 81 & 0.6 & $* * *$ & 22 & 77 & 1 & \#\#\# \\
\hline
\end{tabular}

All figures in percentages, $\mathrm{n}=500, * * * \mathrm{P}<0.0001$ when compared to post test value \#\#\#P<0.0001 when compared to repeat post test value, \#P<0.05 compared to repeat test value, D.K. - Don't Know(Actual questions were full length sentences which have condensed in table).

Significantly increased awareness post intervention was seen regarding importance of correct dose and dosing schedule like refraining of taking double dose if any dose missed $(\mathrm{P}<0.0001)$, dangers of stopping the therapy after symptomatic relief rather than completing the recommended course $(\mathrm{P}<0.0001)$ and dangers of taking high doses anticipating early recovery $(\mathrm{P}<0.05)$.

Significantly increased awareness $(\mathrm{P}<0.0001)$ was also observed post intervention in both post tests regarding rational use of antimicrobials like exact purpose of antimicrobials, dangers of using antimicrobials for common illnesses and previously leftover antimicrobials

Figure 1 represents question number 19 of the instrument we used in this study. In this case four options were given to student and asked to mark as many options he feels correct. Increased level of awareness was observed as percentage of students marking three choices was $37.15 \%$ in post test 1 and $32.5 \%$ in post test 2(repeat post test) as opposed to just $2.5 \%$ in pretest.

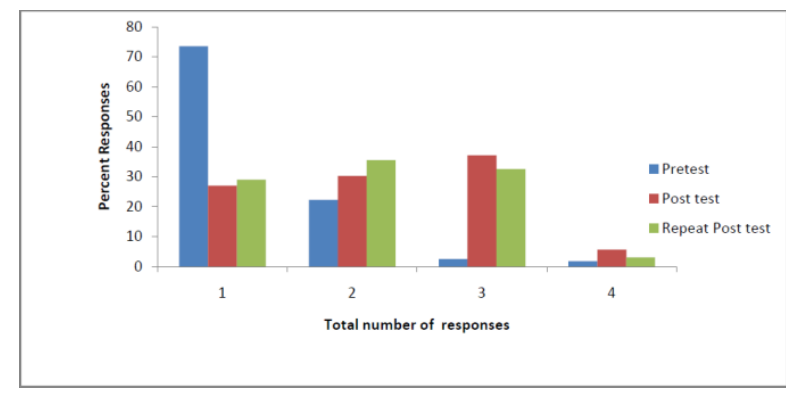

Figure 1: Pre and post responses regarding adverse effects of injections.

Figure 2 represents question number 20 of the questionnaire where four options regarding the precautions to be taken while buying any medicine were given to students and asked them to mark as many answers he feel correct. In this case, increased level of awareness was seen as $53.9 \%$ students in post test 1 and $41.5 \%$ students in post test 2 marked all the four responses as opposed to just $2.25 \%$ students in pretesting.

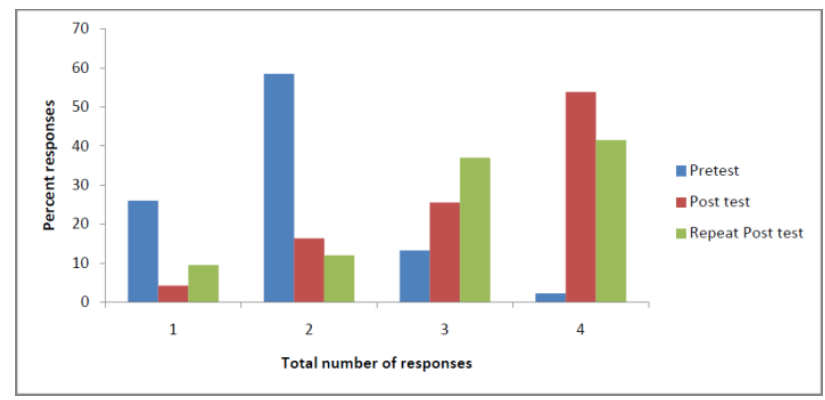

Figure 2: Pre and post test responses regarding precautions to be taken while buying medicines.

\section{DISCUSSION}

The objectives of this study were to evaluate the baseline data about proper medicine use in school children and to see any change in the level of knowledge of the school children after giving an intervention in the form of series of lectures on proper use of medicines. From the pretest results it is obvious that children's knowledge about medicines was extremely insufficient. The pretest results are not surprising considering the widespread problem of wrong practices of medicine use by rural population. Nearly 135 million people living in rural areas lack minimum healthcare facilities. Moreover, majority of "modern allopathic practitioners" are concentrated in urban areas." Illegal practitioners and quacks" are prevalent in rural areas having no idea of the rational use of medicines. Thus people themselves lack knowledge regarding proper use of medicines. ${ }^{9}$

After intervention, awareness increased regarding wrong notions such as superiority and safety of injections over 
tablets, safety of herbal medicines, superiority of costlier medicines, misuse of antimicrobials and analgesics. The knowledge was well retained even after one month of the intervention. This may be due to extensive teaching appropriate to their cognitive development. HameenAnttila and P. Bush have reviewed the cognitive developmental theory in children. According to them, every child passes through four cognitive developmental stages including "sensory motor $(0-2 y)$, preoperational (2-7 y), concrete operational (7-11 y) and formal operational (12 y onwards)." Conceptualized and generalized thinking develops after child is 12 years or older which is lacking in previous three developmental stages. Teaching of medicine use can be easily done if we put more efforts and encouragement to child at this stage. ${ }^{10}$ This is why we selected school children in this age group so as to increase the level of awareness proper use of medicines.

So far, extremely limited amount of data is available from India regarding the level of awareness about proper use of medicines in school children. Teaching proper use of medicine is the most neglected part of the school curriculum in India, moreover there is lack of any specific education program which includes teaching rational use of medicines to school children. Most of the school education programs in India are focusing more on teaching hygiene and sexuality education. That means children learn about medicines mostly from their parents. In rural India, people themselves lack any education about rational use of medicines, moreover their level of literacy and socioeconomic status is very low. It is obvious that children will learn insufficient and inappropriate knowledge about medicine use from them. Previous studies have confirmed this finding that medicine use practices of mother have the greatest influence on children's medicine use behavior. ${ }^{11}$

E-bug is an education program operative in European countries and run by Directorate General for Health and Consumer Protection for the European Commission for creating awareness among the school children about appropriate and safe use of antimicrobials, so as to minimize the adverse effects associated with antimicrobials and to prevent the spread of antibiotic resistance. Lack of such specific education programs in Indian schools is reflected in the poor knowledge about antimicrobials in our study. ${ }^{12,13}$

Rajasekaran et al in his study about injection practices in Southern India reported that patients themselves give more preference to injections even for minor illnesses because of their belief to be more effective and safer than tablets, as reflected in the opinion of $87 \%$ of doctors as the main reason for using a high number of injections for the sake of patient's satisfaction. ${ }^{14}$

We can say that this might be the reason why knowledge regarding injections was poor in our sample as children mostly learn from their parental practices. As per WHO report, people of India regard traditional medicines (Herbal/Ayurvedic) as the safest medicines resulting in widespread self-medication and also use along with the modern medicines which sometimes may lead to harmful interactions. ${ }^{15}$ In one study, Stoelben et al reported $79 \%$ of the school children in Germany in the age group of 15 17 years were aware of the adverse effects of the medicines. However, other studies having younger age group of 7-10 years, children failed to mention any such possibility. ${ }^{16}$ These studies implies that older group of student can very well understands the risk of medicines. This is in accordance to our results as more number of people responded to the question about adverse effects of medicines. $^{17,18}$ In a study by Bozoni et al, health information seeking practices of school correlated directly with age and socioeconomic status of the of the children where older children (11 years or above) of lower socioeconomic status watched more television in order to seek health information they could not obtain from their parents. This might be the reason about low level of awareness about safety of analgesics and vitamins in our study as per report on influence of advertising on children citing that children are extremely vulnerable to readily accept the claims made in the advertisements. ${ }^{19,20}$

In conclusion, level of awareness was very low regarding the proper use of medicines. School children mostly learn about medicines by observing family members or by exposure to media advertising. Harmful medicine use practice by the parents can influence the medicine related health behavior in children. By making them aware about the risks, we can impart a sense of responsibility in using medicines. As adults, especially in rural areas lack proper knowledge about correct use of medicines, being the future medicine users, there is an urgent need for educating children about proper use of medicines if we want our future generation in making rational decisions concerning medicine use. Moreover, schoolchildren can pass their knowledge to their family members and neighbours. In order to formulate effective school health curriculum, more studies regarding attitude, beliefs and questions of school children about medicines in India are necessary. Our study showed that properly timed and meticulously implemented intervention can increase level of awareness about medicines of rural school children which was retained even after one month of the intervention.

\section{Funding: None \\ Conflict of interest: There was no conflict of interest \\ Ethical approval: The study protocol was approved by the Institutional Ethics Committee of Government Medical College, Nagpur}

\section{REFERENCES}

1. Hameen-Anttila K, Airaksinen M, Vainio K, Bush PJ, Ahonen R. Developing a medicine education 
program in Finland: lessons learned. Health Policy 2006;78:272-83.

2. Sloand ED, Vessey JA. Self-medication with common household medicines by young adolescents. Issues Compr Pediatr Nurs 2001;24: 57-67.

3. Katri Hämeen-Anttila, Leena Honkanen, KirstiVainio, The usability of medicine education assignments for seven to nine year-old children. Health Education 2009;109(6):491-506.

4. Hampshire KR, Porter G, Owusu SA, Tanle A, Abane A. Out of reach of children? Young poeple's health-seeking practices and agency in Africa's newly-emerging therapeutic landscapes. Social Science and Medicine 2011;73:702-10.

5. Patel V, Vaidya R, Naik D, Borker P. Irrational drug use in India: A prescription survey from Goa. J Postgrad Med 2005;51:9-12.

6. Dineshkumar B, Raghuram TC, Radhaiah G, KrishnaswamyK. Profile of Drug Use in Urban and Rural India. Pharmacoeconomics 1995;7(4):275374.

7. Dutta A, ChakrabortyS.Practice of rational drug uses in a rural area of $24 \mathrm{pgs}(\mathrm{s})$ in West Bengal. J Adv Pharm Technol Res. 2010 Jul-Sep; 1(3):35864.

8. Bush PJ, Cebotarenco N. Its time children learned about medicines. JPHSR 2010;1:3-8.

9. Patil AV, Somasundaram KV, Goyal RC. Current health scenario in rural India. Aust J Rural Health 2002;10:129-35.

10. KatriHameen-Anttila, Patricia J. Bush. Healthy children's perceptions of medicines: A review. Research in Social and Administrative Pharmacy 2008;4:98-114.

11. Bush PJ, Iannotti RJ. A children's health belief model. Med Care 1990;28:69-86.

12. Donna ML, Cliodna AM, Niels A, Tereza KH, Jette H, Pia T, Kyriakoula M, Raffaella K, Anna OP, et al. What are school children in Europe being taught about hygiene and antibiotic use? J Antimicrob Chemother 2011;66(suppl 5):v13-v21.

13. Cliodna A. M. McNulty, Donna M. Lecky, David Farrell, Patty Kostkova, Niels Adriaenssens, Tereza Koprivová Herotová, Jette Holt, Pia Touboul, Kyriakoula Merakou, Raffaella Koncan, Anna Olczak-Pienkowska, António BritoAvô, José Campos. Overview of e-Bug: an antibiotic and hygiene educational resource for schools. J Antimicrob Chemother 2011;66(suppl 5): v3-v12.

14. Rajasekaran M, Sivagnanam G, Thirumalaikolundusubramainan P, Namasivayam K, Ravindranath $\mathrm{C}$. Injection practices in southern part of India. Public Health 2003;117:208-13.

15. Available from: http://www.searo.who.int/ LinkFiles/WHO_Country_Cooperation_Strategy__India_WHO_CCS-India_supplement.pdf. Accessed 6 August 2012.

16. Stoelben S, Krappweis J, Rossler G, Kirch W. Adolescents' drug use and drug knowledge. Eur J Pediatr 2000;159:608-14.

17. Hameen-Anttila K, Juvonen M, Ahonen R, Bush PJ, Airaksinen M. How well can children understand medicine related topics? Patient Educ Couns 2006;60:171-8.

18. Menacker F, Aramburuzabala P, Minian N, Bush PJ, Bibace R. Children and medicines: what they want to know and how they want to learn. J Soc Adm Pharm 1999;16:38-52.

19. Bozoni K, Kalmanti M, Koukouli S. Perception and knowledge of medicines of primary schoolchildren: the influence of age and socioeconomic status. Eur J Pediatr 2006;165:42-9.

20. Committee on Communications. Children, adolescents and advertising. Pediatrics 2006;118:2563-9.

doi:10.5455/2319-2003.ijbcp20130806

Cite this article as: Bankar MA, Dudhgaonkar SS Promoting the proper use of medicines in rural school children of India. Int J Basic Clin Pharmacol 2013;2:375-80. 